Supporting information for:

\title{
Ship plumes in the Baltic Sea Sulphur Emission Control Area: Chemical characterization and contribution to coastal aerosol concentrations
}

5 Stina Ausmeel ${ }^{1}$, Axel Eriksson ${ }^{1,2}$, Erik Ahlberg ${ }^{1}$, Moa K. Sporre ${ }^{1}$, Mårten Spanne ${ }^{3}$, Adam Kristensson ${ }^{1}$

${ }^{1}$ Division of Nuclear Physics, Lund University, Box 118, 22100 Lund, Sweden

${ }^{2}$ Ergonomics and Aerosol Technology, Lund University, Box 118, 22100 Lund, Sweden

${ }^{3}$ Environment Department, City of Malmö, SE-208 50 Malmö

Correspondence to: Stina Ausmeel (stina.ausmeel@nuclear.lu.se)

10 Number of pages: 5

Number of figures: 5 


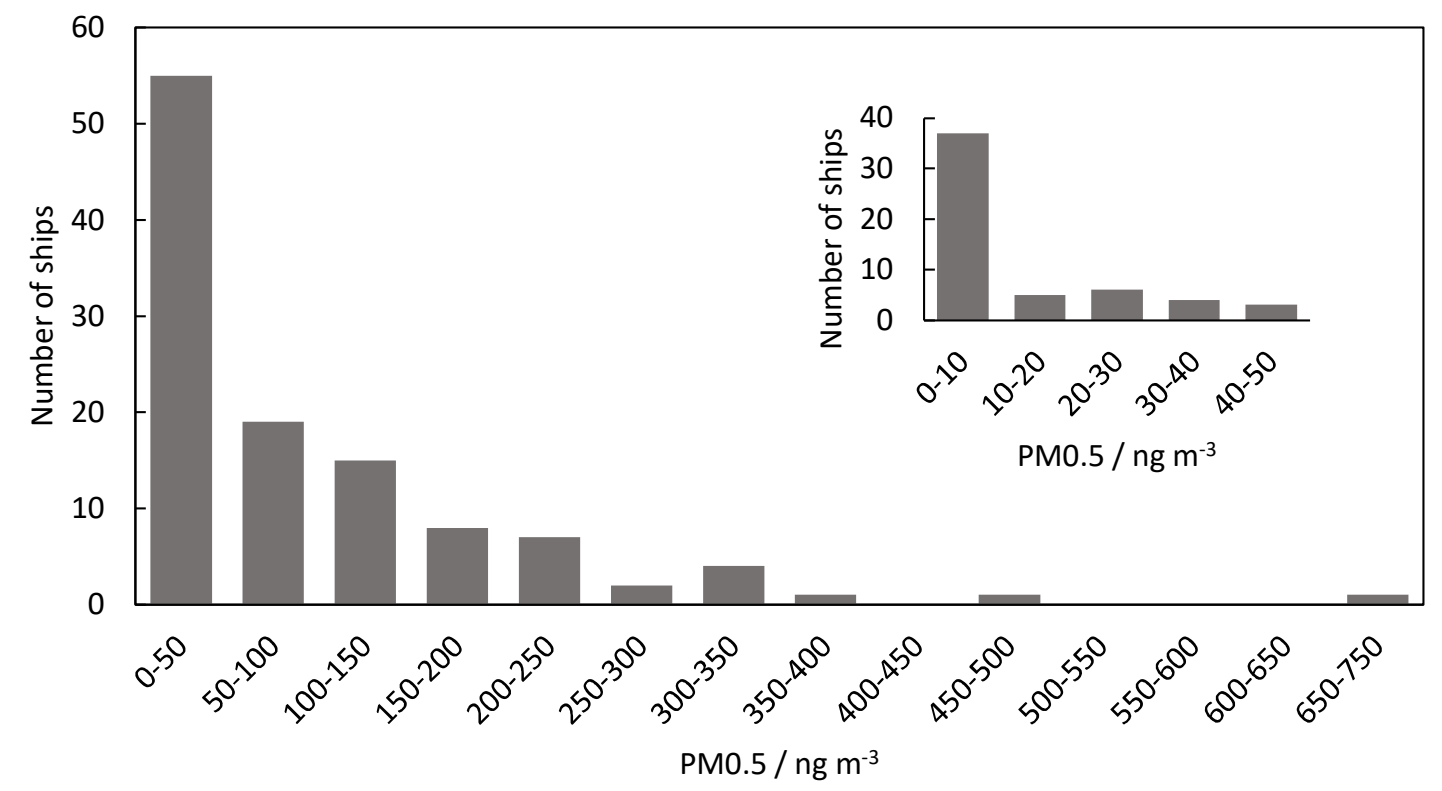

15 Figure S1: Calculated mass concentration contribution from ship plume particle emissions during the winter measurement campaign in Falsterbo. Mass concentration is given in $\mathbf{P M}_{0.5}$ and the frequency of ships with different $\mathrm{PM}_{0.5}$ contribution is given in intervals of $50 \mathrm{ng} \mathrm{m}^{-3}$. The inserted plot shows a more detailed resolution of the lowest mass concentration bin.

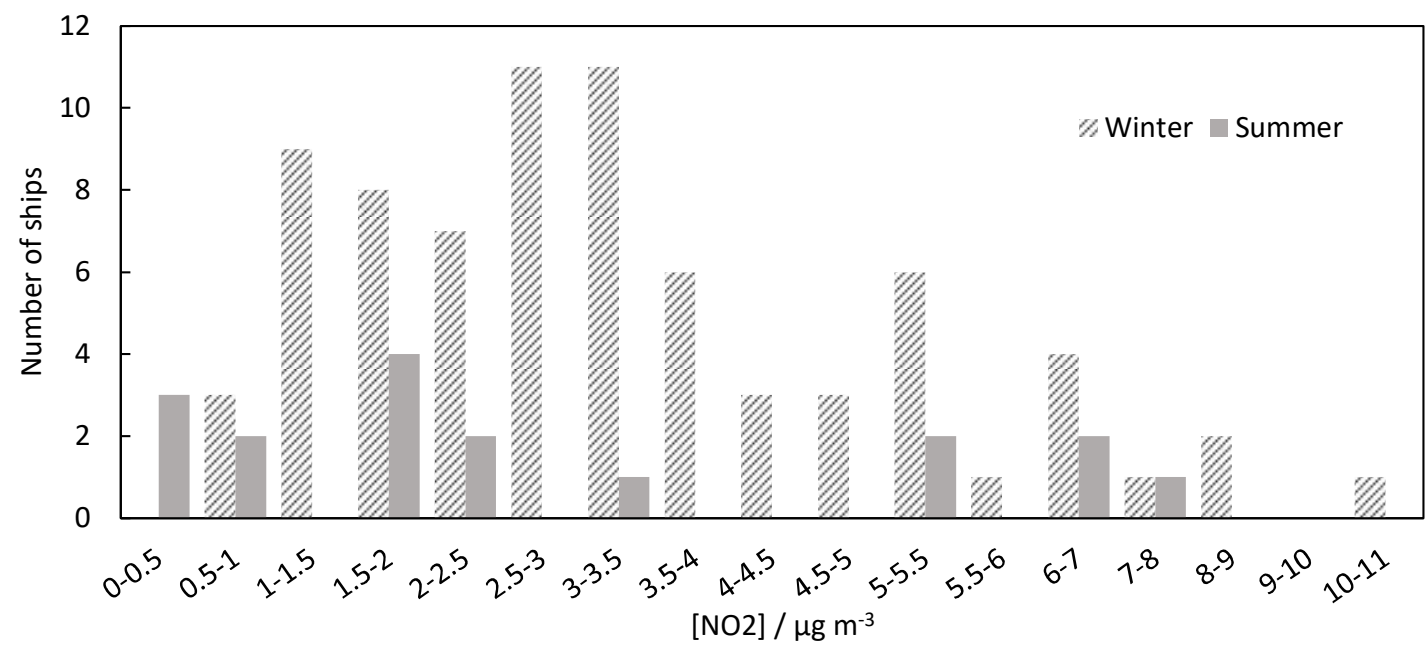

Figure S2: $\mathrm{NO}_{2}$ concentration contribution from ship plume emissions during the winter measurement campaign in Falsterbo. The frequency of ships with different $\mathrm{NO}_{2}$ contributions is given in intervals of $0.5 \mu \mathrm{g} \mathrm{m}^{-3}$. 


\section{Oxidation flow reactor}

$\mathrm{OH}$ exposure in the reactor was calibrated off-line, using the decay of $\mathrm{SO}_{2}$ (Mao et al., 2009). Using calibration parameters, a function using measured $\mathrm{RH}$, temperature and ozone concentration was used to calculate $\mathrm{OH}$ exposure during the field campaign, in a similar manner to Ortega et al. (2013). In our campaign, only one UV lamp was used. By changing the voltage of the lamp, together with naturally changing absolute humidity, a range of ozone and $\mathrm{OH}$ exposures was achieved. Ozone was 2-10 ppm and $\mathrm{OH}$ exposure was $0.7-2.5 \cdot 10^{11}$ molecules $\mathrm{cm}^{-3} \mathrm{~s}$. This translates to about $0.5-2$ days of aging in the atmosphere assuming an average $\mathrm{OH}$ concentration of $1.5 \cdot 10^{6}$ molecules $\mathrm{cm}^{-3}$ (Mao et al., 2009). This OH exposure is low in comparison to previous OFR campaigns. With higher $\mathrm{OH}$ exposure, losses are expected to increase due to fragmentation and evaporation from an increased temperature in the reactor (Lambe et al., 2015; Ortega et al., 2016; Palm et al., 2016a).

Particle diffusion losses of different sizes in the reactor was calculated from the SMPS measurements before and after the PAM was connected, during a two-day period when the reactor lamps were turned off (Figure S3). In general, losses in the reactor are low, with almost no losses at sizes above $100 \mathrm{~nm}$ in mobility diameter. From $\sim 40-100 \mathrm{~nm}$ penetration is about $90 \%$. The loss data for particles smaller than $40 \mathrm{~nm}$ is noisy since ambient concentrations at these sizes were in general low. Because the penetration is high where the ambient particle volume concentration was highest, the average volume losses were on the order of a few percent with an average penetration of $0.99 \pm 0.03$ (one standard deviation).

To assess what portion of low-volatile organic compounds (LVOCs) that condensed onto particles in the reactor, the model of Palm et al.(2016b) was used. This model compares the lifetimes of condensation onto particles with wall loss, fragmentation (approximated as reacting 5 times with $\mathrm{OH}$ ) and residence time of the reactor. The condensation sink was estimated as an average of ambient and reactor size distributions. The wall loss rate was estimated at $0.02 \mathrm{~s}^{-1}$ and a reaction rate with $\mathrm{OH}$ of $1 \times 10^{-11} \mathrm{~cm}^{3}$ molecules ${ }^{-1} \mathrm{~s}^{-1}$. Fractional losses can be seen in figure S4.

On several occasions, (see Figure 4) the OFR processing led to an increase in the mass concentration as measured by the AMS, and as estimated mass concentration from the SMPS distributions. However, while the measured (by AMS) and estimated (from SMPS data) mass concentrations were in good agreement when the OFR was bypassed, OFR processing increased the former more than the latter (see Figure S5). This is possibly due to changes in AMS sensitivity, specifically the collection efficiency (CE) due to particle bounce of the vaporizer. We have applied a CE of 0.5 throughout the dataset. 


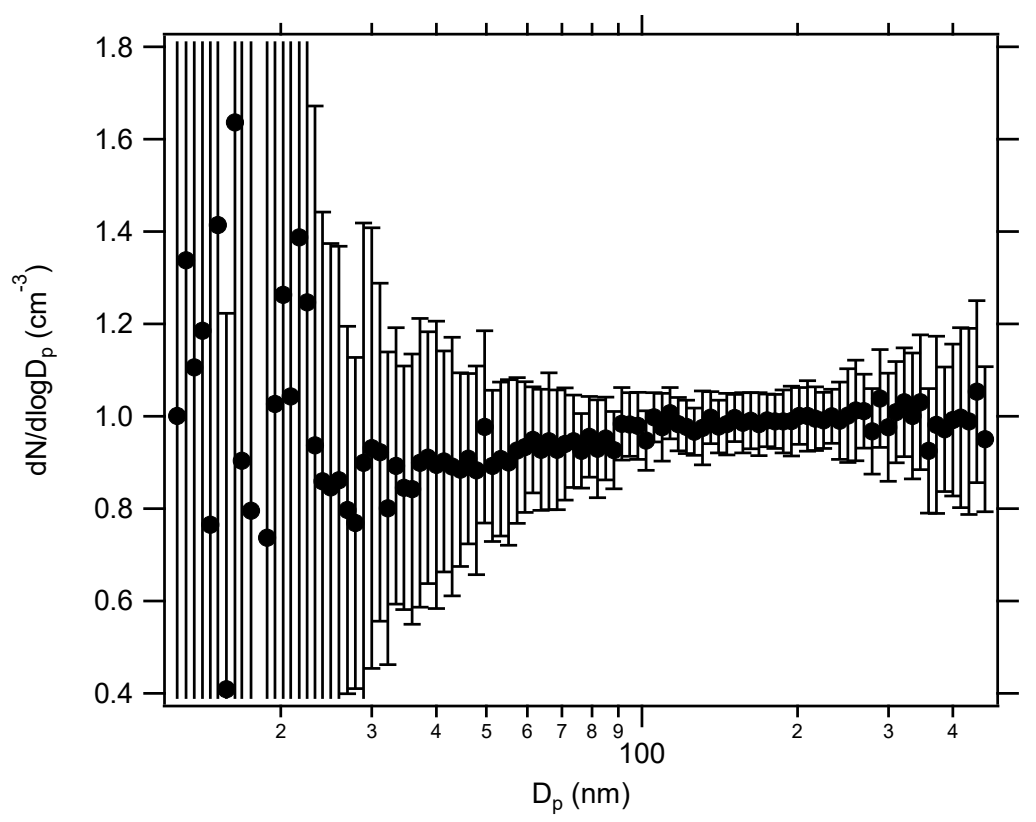

Figure S3: Penetration in the reactor as a function of particle size calculated using ambient particle concentrations when the reactor lamps were turned off. Data at the low and high end of the spectrum are noisy due to low ambient particle concentrations.

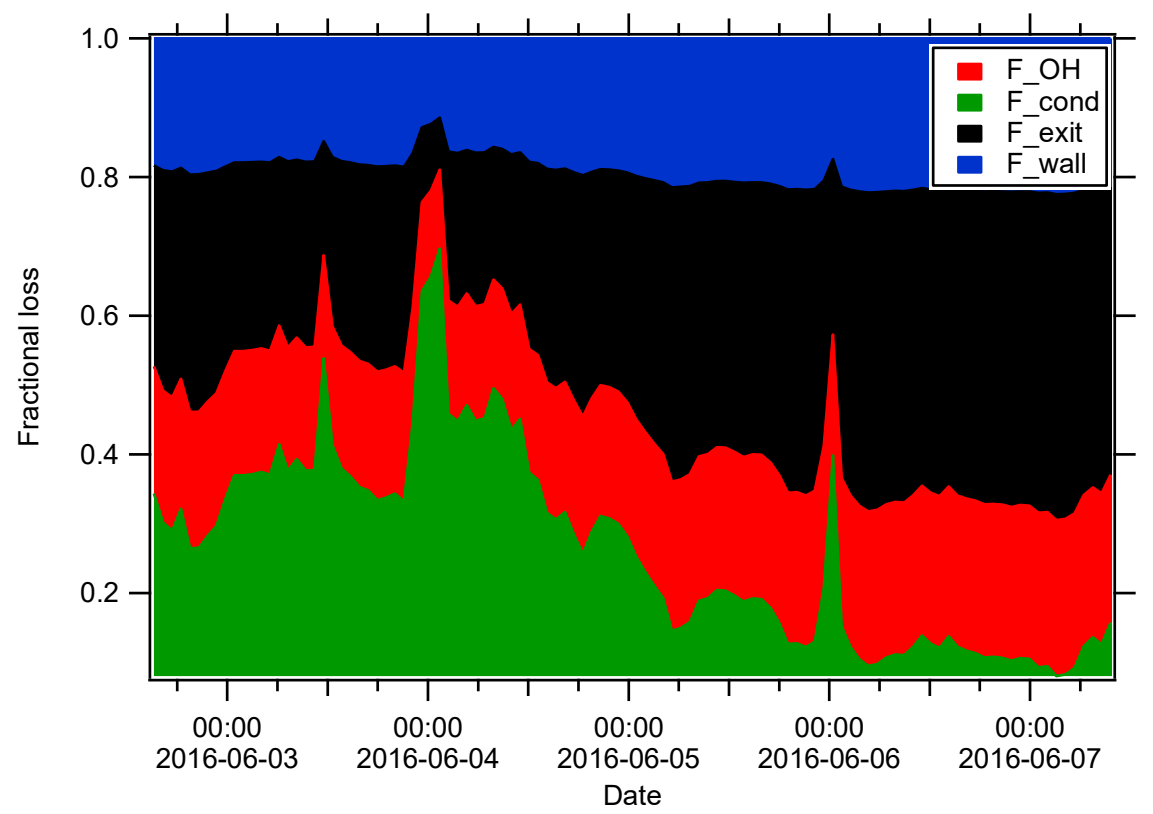

Figure S4: The fractional fate of LVOCs. The fraction that condenses ( $F$ cond) depends on the condensation sink which was calculated as an average of ambient and reactor output. The fraction lost to fragmentation $\left(F_{-} O H\right)$ is calculated using the lifetime for reacting five times with $\mathrm{OH}$. A fraction is lost to the walls of the chamber (F_wall) and the remaining fraction (F_exit) is what penetrates the OFR. 


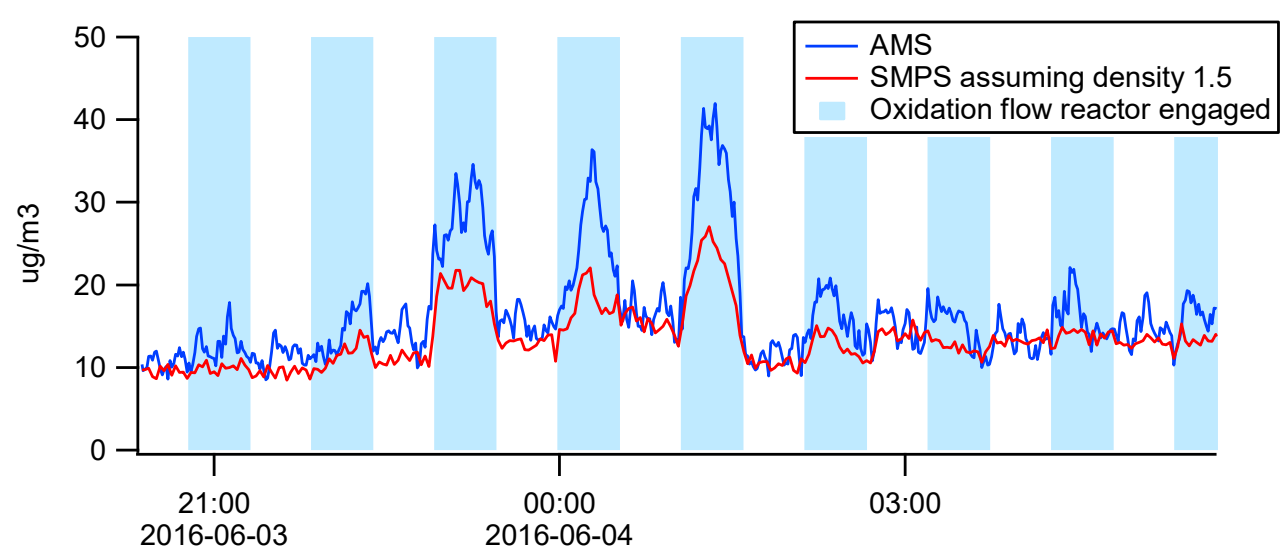

Figure S5: Comparison of the total particulate mass concentration measured by the AMS and estimated mass concentration from the SMPS size distributions during the oxidation flow reactor experiment shown in Fig. 4.

\section{References}

Lambe, A., Chhabra, P., Onasch, T., Brune, W., Hunter, J., Kroll, J., Cummings, M., Brogan, J., Parmar, Y., and Worsnop, D.: Effect of oxidant concentration, exposure time, and seed particles on secondary organic aerosol chemical composition and yield, Atmos. Chem. Phys., $15,3063-3075,2015$

65 Mao, J., Ren, X., Brune, W., Olson, J., Crawford, J., Fried, A., Huey, L., Cohen, R., Heikes, B., and Singh, H.: Airborne measurement of OH reactivity during INTEX-B, Atmos. Chem. Phys., 9, 163-173, 2009.

Ortega, A., Day, D., Cubison, M., Brune, W., Bon, D., De Gouw, J., and Jimenez, J.: Secondary organic aerosol formation and primary organic aerosol oxidation from biomass-burning smoke in a flow reactor during FLAME-3, Atmos. Chem. Phys., 13, 11551-11571, 2013.

Ortega, A. M., Hayes, P. L., Peng, Z., Palm, B. B., Hu, W., Day, D. A., Li, R., Cubison, M. J., Brune, W. H., and Graus, M.: Real-time

70 measurements of secondary organic aerosol formation and aging from ambient air in an oxidation flow reactor in the Los Angeles area, Atmos. Chem. Phys., 16, 7411-7433, 2016.

Palm, B. B., Campuzano-Jost, P., Ortega, A. M., Day, D. A., Kaser, L., Jud, W., Karl, T., Hansel, A., Hunter, J. F., and Cross, E. S.: In situ secondary organic aerosol formation from ambient pine forest air using an oxidation flow reactor, Atmos. Chem. Phys., 16, 2943-2970, 2016a.

75 Palm, B. B., Campuzano-Jost, P., Ortega, A. M., Day, D. A., Kaser, L., Jud, W., Karl, T., Hansel, A., Hunter, J. F., Cross, E. S., Kroll, J. H., Peng, Z., Brune, W. H., and Jimenez, J. L.: In situ secondary organic aerosol formation from ambient pine forest air using an oxidation flow reactor, Atmos. Chem. Phys., 16, 2943-2970, 10.5194/acp-16-2943-2016, 2016 b. 